\title{
Differential Expression of Guanosine Triphosphate Binding Proteins in Men at High and Low Risk for the Future Development of Alcoholism
}

\author{
Gary S. Wand, ${ }^{\star *}$ Claire Waltman, ${ }^{\star}$ Christopher S. Martin, ${ }^{5}$ Mary E. McCaul, ${ }^{\ddagger}$ Michael A. Levine, ${ }^{\star}$ and David Wolfgang \\ Departments of *Medicine and ${ }^{\ddagger}$ Psychiatry, The Johns Hopkins University School of Medicine, Baltimore, Maryland 21205; and \\ ${ }^{\S}$ Department of Psychiatry, University of Pittsburgh Medical Center, Pittsburgh, Pennsylvania 15213
}

\begin{abstract}
We evaluated G-proteins that are components of adenylyl cyclase (AC) signal transduction in erythrocyte and lymphocyte membranes from 26 family history positive (FHP) nonalcoholic and 26 family history negative (FHN) nonalcoholic subjects. Subjects were classified as FHP if their father met criteria for alcohol dependence; as FHN, if there was no history of alcoholism in any first or second degree relatives. Immunoblot analysis indicated that levels of erythrocyte membrane Gs $\alpha$ from FHP subjects were greater than levels in FHN subjects $(171 \pm 11$ vs $100 \pm 6, P<0.001)$. To confirm the results of the immunoblot analysis, Gs $\alpha$ was quantitated by cholera toxin-dependent $\left[{ }^{32} \mathrm{P}\right] \mathrm{ADP}$-ribosylation. Levels of erythrocyte [ $\left.{ }^{32} \mathrm{P}\right] \mathrm{ADP}$-ribose-Gs $\alpha$ from FHP subjects were greater than levels in FHN subjects $(236 \pm 28$ vs $100 \pm 14, P$ $<0.001)$. Gsa levels did not correlate with age or alcohol consumption. By contrast to differences in Gsa, immunoblot analysis showed similar levels of $\mathrm{Gi}(2) \alpha$ and $\mathrm{Gi}(3) \alpha$ in erythrocyte membranes of FHP and FHN subjects. Pertussis toxin-catalyzed [ ${ }^{32}$ P]ADP-ribosylation of Gi-like G-proteins confirmed the immunoblot observations. Lastly, compared to FHN subjects, FHP subjects had enhanced Gs $\alpha$ expression in lymphocyte membranes as well $(138 \pm 11$ vs $100 \pm 5.5$; $P<0.02$ ). In summary, compared to FHN nonalcoholic men, FHP nonalcoholic men had greater levels of the stimulatory G-protein, Gsa, in erythrocyte and lymphocyte membranes. Enhanced expression of Gs $\alpha$ may be a marker of increased risk for the future development of alcoholism. (J. Clin. Invest. 1994. 94:1004-1011.) Key words: guanine nucleotide binding proteins $\cdot$ adenylyl cyclase $\cdot$ biological markers • alcoholism
\end{abstract}

\section{Introduction}

Familial clustering of alcoholism has been attributed to both inherited and environmental factors $(1,2)$. During the past decade, the significance of genetic vulnerability in the development of alcoholism has been demonstrated in a number of studies. For example, monozygotic twins show a twofold higher

Address correspondence to Gary S. Wand, MD, Associate Professor of Medicine and Psychiatry, Division of Endocrinology, Ross Bldg., Room 1032, The Johns Hopkins University School of Medicine, 720 Rutland Avenue, Baltimore, MD 21205.

Received for publication 8 June 1993 and in revised form 18 April 1994.

J. Clin. Invest.

(C) The American Society for Clinical Investigation, Inc. 0021-9738/94/09/1004/08 $\$ 2.00$

Volume 94, September 1994, 1004-1011 concordance rate for alcoholism than dizygotic twins $(2,3)$. In addition, sons of alcoholic fathers who are adopted before three months of age and raised in nonalcoholic households have a fourfold greater risk of developing alcoholism than sons of nonalcoholic fathers under the same circumstances $(4,5)$. These findings have stimulated a search for biochemical, hormonal, neurophysiological, and genetic markers to identify nonalcoholic individuals at increased risk of developing alcoholism (610). There is growing evidence for differential sensitivity to the effects of ethanol secondary to differences in the metabolism of ethanol and/or differences in tissue sensitivity to ethanol (6, $7,9,10)$.

The adenylyl cyclase (AC) ${ }^{1}$ signal transduction pathway has been proposed as a potential marker for vulnerability to alcoholism. The AC complex is composed of three membrane-bound proteins: (a) receptors; (b) guanine nucleotide binding proteins (G-proteins); and (c) adenylyl cyclase, the membrane-bound enzyme that converts Mg-ATP to cAMP. G-proteins couple cell surface membrane receptors to adenylyl cyclase. AC is under dual control by stimulatory (Gs) and inhibitory (Gi) G-proteins.

Alcohol can perturb the AC system both in vitro and in vivo (11). Several lines of evidence indicate that alcoholic individuals have abnormal adenylyl cyclase signal transduction and that genetic determinants may account for some of these differences. Stimulated cAMP production in freshly isolated platelets and lymphocytes is reduced in alcoholics compared to nonalcoholic controls $(11,12)$. Moreover, after multiple generations in culture, lymphocytes from alcoholics not only recover their responsiveness but develop enhanced sensitivity to factors that stimulate cAMP (13). Work by Palmour et al. supports these observations and shows that cultured lymphocytes from FHP men (14) as well as "ethanol-preferring" Vervet monkeys (15) have increased AC signal transduction. The persistence of differences in AC signal transduction after several generations in culture between lymphocytes from alcoholics and nonalcoholics suggests that the alcoholics may have an abnormality in AC signal transduction that predates the development of alcoholism. The finding that lymphocytes and platelets of alcoholics show impaired stimulation of AC by a variety of receptor ligands and a nonhydrolizable GTP analogue is consistent with an abnormality in the stimulatory G-protein, Gs $\alpha$ that couples receptor activation to AC (11).

We speculate that inherited differences in the susceptibility of AC signal transduction to the effects of ethanol account for some of the inherited differences in susceptibility to the effects of ethanol. Therefore, in this study, we compared membrane G-

1. Abbreviations used in this paper: $\mathrm{AC}$, adenylyl cyclase; $\mathrm{AHO}, \mathrm{Al}-$ bright's hereditary osteodystrophy; CTX, cholera toxin; CV, coefficient of variance; FH-RDC, Family History-Research Diagnostic Criteria; FHN, family history negative; FHP, family history negative; PTX, pertussis toxin; RBC, red blood cell. 
protein content from erythrocyte and lymphocytes membranes derived from nonalcoholic subjects at high and low risk for alcoholism.

\section{Methods}

Subject population. Subjects were recruited by newspaper advertisements. On the basis of a mailed questionnaire, subjects were invited for an interview in which personal and family alcohol and drug use patterns were assessed using the Family History-Research Diagnostic Criteria (FH-RDC) format (16). Exclusion criteria included chronic medical illness, DSM III-R Axis I disorders, and alcohol/drug abuse or dependence. All subjects were medication-free and were asked to abstain from ethanol for $48 \mathrm{~h}$ prior to study. Subjects were classified as family history positive (FHP) if at least the father met criteria for alcohol dependence. Subjects were classified as family history negative (FHN) if no first or second-degree relatives met criteria for alcohol abuse or dependence. The FHP $(n=26)$ and FHN $(n=26)$ subjects were similar in age and in the number of drinks consumed per week. Two FHN and four FHP subjects were African-American; one FHN and two FHP subjects were female; all other subjects were caucasian males. Informed consent was obtained from all subjects, and subjects received financial compensation for participation. The study protocol was approved by the Johns Hopkins Medical Institutions Joint Committee On Clinical Investigation. Table I provides data on the age, drinking practices, and family history status of subjects in the two groups.

Membrane preparation and G-protein analysis. Blood was withdrawn from a peripheral vein of each subject between $0800-1000$ hours. Erythrocyte membranes were prepared as previously described (17) and membranes were resuspended in buffer containing $1 \mathrm{mM}$ Tris- $\mathrm{HCl}(\mathrm{pH}$ 7.4), $1 \mathrm{mM}$ EDTA, $5 \mu \mathrm{g} / \mathrm{ml}$ leupeptin, $0.3 \mathrm{mg} / \mathrm{ml}$ phenylmethylsulfonylfluoride, and $1 \mathrm{mM}$ dithiothreitol and stored at $-70 \mathrm{C}$. Lymphocytes were isolated from $120 \mathrm{~cm}^{3}$ whole blood by ficoll density gradient centrifugation (Histopaque-1077, Sigma Chemical Co., St. Louis, MO) (18). Differential cell counts were performed using a modified Wright's stain. B and T lymphocyte typing was performed using Simultest reagents (Becton Dickinson Vacutainer Systems, Rutherford, NJ) and a FACScan flow cytometer (Becton Dickinson Vacutainer Systems) or Cyto-Stat/Coulter Clone (Coulter Immunology, Hialeah, FL) and a Coulter EPICS Profile I(Coulter Immunology). To prepare membranes (18), lymphocytes were disrupted by nitrogen cavitation at $110 \mathrm{~kg} / \mathrm{cm}^{2}$ for $15 \mathrm{~min}$ in $25 \mathrm{mM}$ Hepes (4-[2-hydroxethyl]-1-piperazine-ethanesulfonic acid), $10 \%$ sucrose ( $\mathrm{pH} 7.4$ ). The broken cells were collected and washed twice by centrifugation at $100,000 \mathrm{~g}$ for $30 \mathrm{~min}$ in $1 \mathrm{mM}$ Tris, 1 mM EDTA (TE), pH 7.4. The final pellet (crude membrane preparation) was suspended in $\mathrm{TE}$ and stored at $-70^{\circ} \mathrm{C}$. Protein concentration was determined by bicinchoninic acid reaction with BSA as standard (18).

For immunoblot analysis (19), membrane proteins $(75 \mu \mathrm{g})$ were fractionated by electrophoresis through $10 \%$ SDS-polyacrylamide gels ( $10 \%$ acrylamide, $0.13 \%$ phenylpiperazine). Proteins were electrophoretically transferred to polyvinylidine difluoride filters using a transfer bath containing 10\% methanol, $0.01 \mathrm{M} \mathrm{3-(cyclohexlamino)-1-pro-}$

Table I. Subject Information

\begin{tabular}{|c|c|c|}
\hline Information & FHP & FHN \\
\hline No. & 26 & 26 \\
\hline Age & $\begin{array}{c}23.5 \pm 0.5 \\
(19-30)\end{array}$ & $\begin{array}{c}23.5 \pm 0.6 \\
(20-30)\end{array}$ \\
\hline Alcoholic father & $100 \%$ & 0 \\
\hline Alcoholic second degree relative(s) only & 0 & 0 \\
\hline Drinks/wk & $9 \pm 1.9$ & $8 \pm 1.6$ \\
\hline
\end{tabular}

panesulfonic acid $\mathrm{pH}$ 11.0). After transfer, filters were stained with Coomassie blue to ascertain transfer efficacy. Filters were incubated for $2 \mathrm{~h}$ at room temperature in $50 \mathrm{mM}$ Tris- $\mathrm{HCl}, 138 \mathrm{mM} \mathrm{NaCl}, 2 \mathrm{mM}$ $\mathrm{MgCl}_{2}, \mathrm{pH} 7.4 \mathrm{~T}$ (TBS) containing 3\% BSA, $0.1 \%$ Tween-20, $0.02 \%$ $\mathrm{NaN}_{3}$, and washed twice for 5 to $10 \mathrm{~min}$ with TBS containing $0.2 \%$ SDS, $2 \%$ Nonidet P-40. Filters were incubated overnight at room temperature with specific primary antisera in TBS containing $1 \%$ BSA, $0.05 \%$ Tween-20, $0.02 \% \mathrm{NaN}_{3}$, and $2 \%$ Nonidet P-40. Filters were washed twice for $30 \mathrm{~min}$ in wash buffer (TBS, $0.2 \%$ SDS, $2 \%$ Nonidet $\mathrm{P}-40$ ). Antibody bound to protein was detected using ${ }^{125}$ I-protein A $(0.5 \mu \mathrm{Ci} / \mathrm{ml})$ and autoradiography at $-70^{\circ} \mathrm{C}$ with Dupont intensifying screens. Autoradiographic image intensities were determined by two dimensional densitometry (Molecular Dynamics Inc., Sunnyvale, CA). Antiserum C584 (Janet Robishaw, Geisinger Clinic, Danville, PA) recognizes COOH-terminal amino acids (325-339) of both the 45- and $52-\mathrm{kD}$ forms of Gs $\alpha$ (19). Antiserum AS (Alan Spiegel, National Institutes of Health) recognizes $\mathrm{Gi}(2) \alpha$ and $\mathrm{Gi}(1) \alpha>\mathrm{Gi}(3) \alpha$ (19). Antiserum A56 (Janet Robishaw) recognizes $\mathrm{Gi}(3) \alpha$ and $\mathrm{Gi}(1) \alpha(19)$. Antiserum A54 recognizes $\mathrm{Gi}(2) \alpha(20)$. Antisera GC4 (Alan Spiegel) recognizes amino acids $127-139$ of $\mathrm{G} \beta 1$ and $\mathrm{G} \beta 2$ (19).

To verify that the Gs $\alpha$ antisera was identifying the same protein as labeled in the presence of $\mathrm{CT}$, and to verify that the $\mathrm{Gi}(2) \alpha$ and $\mathrm{Gi}(3) \alpha$ antisera were identifying the same proteins labeled in the presence of PT, the following protocol was followed: Membranes were first labeled in the presence of PT or CT, resolved by SDS-PAGE, transferred to polyvinyldifluoride (Millipore Corp., Bedford, MA) membranes and then exposed to film for development of the first autoradiograph. The same membranes were then probed with specific antisera, and G-proteins were visualized by using a chemiluminescence second antibody (Amersham Intl., Buckinghamshire, England) for a brief $10 \mathrm{~s}$ exposure (21). Filters were then exposed to film for development of the second autoradiograph. Because of marked differences in exposure time for both techniques, this protocol allowed us to visualize on one gel, the same proteins, labeled by both techniques.

Immunoblot analysis of membranes was performed in triplicate for each subject. After being normalized to a pooled standard membrane preparation run in triplicate on each gel, the autoradiographic image intensity for each subject was expressed as a percentage of the mean image intensity of the FHN group. Immunoblots were exposed to x-ray film for varying periods of time in order to optimize signal detection and to ensure that autoradiographic images were within the linear range of sensitivity for the $\mathrm{x}$-ray film. Intraassay and interassay coefficient of variance $(\mathrm{CV})$ are $12 \%$ and $13 \%$, respectively. The variability of the Gs $\alpha$ signal in subjects over time was also examined. To this end, blood was drawn from the same subjects on three separate occasions over a 6-mo period and red blood cell (RBC) membranes were prepared. The CV for the Gs $\alpha$ signal over this time period was $14 \%$.

Bacterial toxin-dependent ADP-ribosylation. G-protein levels were also quantified by measuring the bacterial-dependent $\left[{ }^{32} \mathrm{P}\right]$ ADP-ribose incorporation. To analyze Gs $\alpha$, cholera toxin (CTX) was used: Membrane proteins $(75 \mu \mathrm{g})$ were incubated in duplicate at $32^{\circ} \mathrm{C}$ for $30 \mathrm{~min}$ in the presence of $15 \mathrm{mM}$ Tris- $\mathrm{HCl}(\mathrm{pH} 8.0), 1 \mathrm{mM}$ EDTA, $10 \mathrm{mM}$ thymidine, $1 \mathrm{mM}$ ATP, $1 \mathrm{mM}$ guanosine triphosphate (GTP), $10 \mathrm{mM}$ $\mathrm{MgCl}_{2}, 2 \mathrm{mM}$ dithiothreitol, $300 \mathrm{mM}$ potassium phosphate, and $10^{7}$ cpm [ $\left.{ }^{32} \mathrm{P}\right] \mathrm{NAD}(25 \mu \mathrm{M})$ in a total volume of $60 \mu \mathrm{l}$ containing $10 \mu \mathrm{g}$ CTX (List Biological Laboratories, Inc., Campbell, CA) that had been activated as previously described (22). The reaction was terminated by addition of $1 \mathrm{ml}$ of $15 \mathrm{mM}$ Tris-HCl, $1 \mathrm{mM}$ EDTA, ( $\mathrm{pH} \mathrm{8.0),} \mathrm{and} \mathrm{the}$ membranes were collected by centrifugation. The pellets were resuspended in electrophoresis buffer and analyzed by electrophoresis through $10 \%$ SDS polyacrylamide gels. The gels were then stained, destained, and autoradiographed at $70^{\circ} \mathrm{C}$ using Lighting Plus intensifier screens (DuPont Instruments, Wilmington, DE). To quantify Gi $\alpha$ proteins, pertussis toxin (PTX) was used: membrane proteins $(75 \mu \mathrm{g})$ were incubated in a final volume of $60 \mu \mathrm{l}$ at $32^{\circ} \mathrm{C}$ in the presence of $15 \mathrm{mM}$ Tris-HCl (pH 8.0), $1 \mathrm{mM}$ EDTA, $10 \mathrm{mM}$ thymidine, $1 \mathrm{mM}$ ATP, 1 mM GTP, $2 \mathrm{~mm}$ dithiothreitol, $10^{7} \mathrm{cpm}\left[{ }^{32} \mathrm{P}\right] \mathrm{NAD}(25 \mu \mathrm{M})$, and $5 \mu \mathrm{g}$ PTX (List Biological Laboratories, Inc., Campbell, CA) that had been 
B
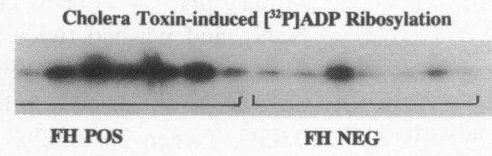

Gs $\alpha$ PROTEIN LEVEL

A

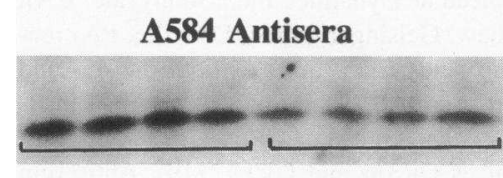

FH POS
FH NEG
Figure 1. (A) Representative immunoblot of erythrocyte membrane Gs $\alpha$ protein content in FHP and FHN nonalcoholic men. Membranes samples were subjected to SDSPAGE and then transferred to a polyvinylidene difluoride membrane as described. Immunodetection was completed using rabbit antisera to specific G-protein subunits followed by ${ }^{125}$ I-labeled protein A. The Gs $\alpha$ antisera recognized a $45-\mathrm{kD}$ band. $(B)$ Representative autoradiograph of cholera toxin-catalyzed [ $\left.{ }^{32} \mathrm{P}\right] \mathrm{ADP}$-ribosylation of erythrocyte membranes in FHP and FHN nonalcoholic men. Membrane samples were incubated with ${ }^{32} \mathrm{P}-\mathrm{NAD}$ and activated cholera toxin as described in methods. Protein were resolved by SDS-PAGE. Estimated molecular weight is based on mobility of $14.3-200-\mathrm{kD}$ molecular weight standards. Cholera toxin labeling recognized a single $45-\mathrm{kD}$ protein. (C) Representative immunoblot and pertussis toxin-catalyzed [ $\left.{ }^{32} \mathrm{P}\right] \mathrm{ADP}$-ribosylation of erythrocyte membrane G-proteins. PT, pertussis toxin; labeling in the presence of pertussis toxin identified a predominant 42-kD band and less intense 40-kD band. activated as described previously (22). After $30 \mathrm{~min}$ of incubation, the samples were processed as described above for CTX-treated samples.

Assessment of Gs biological activity. Erythrocyte membrane proteins were extracted by suspension $(3 \mathrm{mg} / \mathrm{ml}$ protein $/ \mathrm{ml})$ in $10 \mathrm{mM}$ Tris- $\mathrm{HCl}$, pH 7.5 containing $10 \mathrm{mM} \mathrm{MgCl}, 0.1 \mathrm{mM}$ EDTA, $1 \mathrm{~mm}$ DTT, and $0.2 \%$ Lubrol PX. After incubation on ice overnight, the suspension was centrifuged $\left(20,000 \mathrm{~g}\right.$ for $30 \mathrm{~min}$ at $4^{\circ} \mathrm{C}$ ) and supernatant (soluble extract) were recovered (22). Aliquots of soluble extracts were heated to $65^{\circ} \mathrm{C}$ for $1 \mathrm{~h}$ to inactivate both adenylyl cyclase and Gs $\alpha$. The indicated volumes of soluble extract plus heated extract (to maintain a constant concentration of detergent and protein) were added to cyc-membranes $(30 \mu \mathrm{g})$ to reconstitute a Gs-coupled AC. Adenylyl cyclase activity was assayed as previously described (18) in $100 \mu \mathrm{l}$ final volume (10 $\mu \mathrm{g}$ cycmembranes/tube) containing $0.1 \mathrm{mM}\left[\alpha{ }^{32} \mathrm{P}\right] \mathrm{ATP}(1 \mu \mathrm{Ci}), 2.8 \mathrm{U}$ creatine phosphokinase, $5 \mathrm{mM}$ creatine phosphate, $1.5 \mathrm{mM} \mathrm{MgCl}_{2}, 19.2 \mathrm{mg} \%$ BSA, $50 \mathrm{mM}$ Na-Hepes (pH 7.6), $0.3 \mathrm{mM} \mathrm{KCl}, 0.2 \mathrm{mM}$ cAMP, $1 \mathrm{mM}$ DTT, and $10 \mu \mathrm{M}$ GTP $\gamma \mathrm{S}$.

Statistics. Analyses of group differences in measures of G-protein measures were conducted with $t$ tests. In the case of data distributions with significant positive skew, group differences also were tested with $t$ tests on log-transformed data, and the nonparametric Wilcoxin twosample rank sum test. Finally, for measures that showed group differences, multiple regressions were used to examine the proportion of variance accounted for by family history status after first accounting for

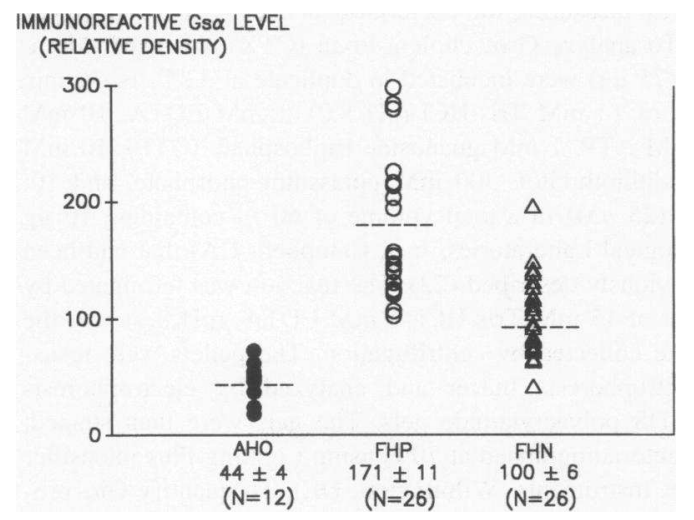

Figure 2. Immunoblot analysis of erythrocyte membrane Gs $\alpha$ protein levels in FHP and FHN nonalcoholic men and patients with AHO. Relative autoradiographic densities of Gs $\alpha$ are plotted in 26 FHP subjects, 26 FHN subjects, and 12 patients with AHO. the influence of age and the average number of drinks consumed per week. These analyses were run on the full samples in the two groups ( $n=26$ per group), and on a subset of subjects carefully matched for gender, age, and alcohol consumption practices.

\section{Results}

Gs $\alpha$ membrane content. Erythrocyte membranes from 26 FHP nonalcoholic men, 26 FHN nonalcoholic men, and 12 patients with Albright's hereditary osteodystrophy (AHO) were subjected to immunoblot analysis using anti-Gs $\alpha$ peptide antisera. A single band with apparent molecular weight of $45 \mathrm{kD}$ was detected in each membrane sample (Fig. $1 A$ ). Quantitative analysis indicated that levels of erythrocyte membrane Gs $\alpha$ were greater in FHP subjects than in FHN subjects (171 \pm 11 vs $100 \pm 6, t=5.5, P<0.001$; Fig. 2). The patients with AHO had levels of Gs $\alpha$ protein that were significantly less than either the FHN or FHP subjects (Fig. 2, 44 $\pm 4 ; P<0.001$ ). To confirm the results of the immunoblot analysis, we assessed cholera toxin-induced (CT) labeling of Gs $\alpha$, a technique that also permits quantification of Gs $\alpha$. Cholera toxin catalyzed the $\left[{ }^{32} \mathrm{P}\right]$ ADP-ribosylation of a single $45-\mathrm{kD}$ band (Fig. $1 \mathrm{~B}$ ). Chol-

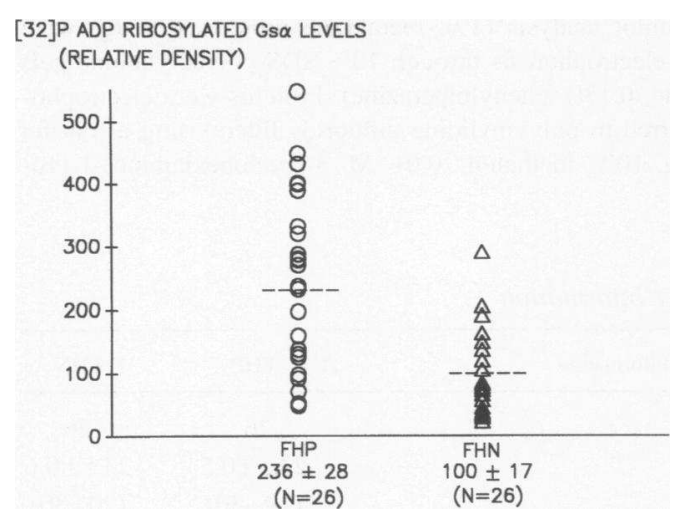

Figure 3. Analysis of erythrocyte membrane Gs $\alpha$ protein by cholera toxin-catalyzed $\left[{ }^{32} \mathrm{P}\right] \mathrm{ADP}$-ribosylation in FHP and FHN nonalcoholic men. Relative autoradiographic densities of Gs $\alpha$ are plotted in 25 FHP subjects and 26 FHN subjects. 


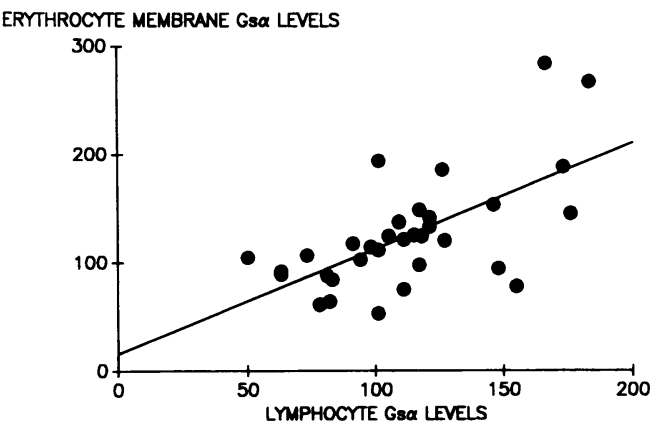

Figure 4. Correlation of Gs $\alpha$ content in erythrocyte and lymphocyte membranes. Lymphocyte and erythrocyte membrane Gs $\alpha$ content.

era toxin-dependent $\left[{ }^{32} \mathrm{P}\right] \mathrm{ADP}$-ribosylation of Gs $\alpha$ was significantly greater in erythrocyte membranes from FHP subjects than in membranes from FHN subjects $(236 \pm 28$ vs $100 \pm 14, t$ $=4.4, P<0.001$; Fig. 3). CT and immunoblot measures of Gs $\alpha$ correlated $r=0.61(n=51, P<0.001)$. Neither cholera toxin nor Gs $\alpha$ immunoblot measures were significantly correlated with age, or with drinks consumed per week.

Because immunoblot and CT distributions in erythrocyte membranes showed significant positive skew, we log-transformed these data, and were successful in inducing normality. Group differences on the log-transformed data were tested to ensure that group differences were not merely due to a few influential outliers. FHP subjects had significantly higher scores than did FHN subjects for log-transformed Gs $\alpha$ antisera data ( $t$ $=6.1, P<0.001)$, and for log-transformed CT data $(t=4.4$, $P<0.001)$. The log-transformed data fit assumptions for the appropriate use of parametric statistics. Nevertheless, to provide a more conservative test of group differences, we performed the nonparametric Wilcoxin two-sample rank sum test on the antisera and CT data. Once again, FHP subjects showed greater Gs $\alpha$ expression, as indicated by antisera data $(z=5.6, P$ $<0.001)$, and CT data $(z=4.2, P<0.001)$.

To estimate the proportion of variance in erythrocyte Gs $\alpha$ measures accounted for by family history, separate hierarchical multiple regression analyses were performed to predict Gs $\alpha$ antisera scores, and CT scores. Age and drinks per week were entered first, followed by family history, to estimate the effects of family history status after accounting for the effects of age and alcohol consumption. For both antisera and CT data, neither age nor drinks per week were significant predictors in the regressions. For antisera data, family history produced a large incremental $r$-squared value of 0.37 . The final beta of 0.61 for family history was significant $(P<0.001)$. For CT scores, family history produced an incremental gain of 0.25 in $r$-squared. The final beta of 0.51 for family history was significant $(P<0.001)$. (Results were similar when log-transformed antisera and CT values were used in multiple regressions.)

To assess whether enhanced expression of Gs $\alpha$ in FHP men was unique to the RBC or generalized to other tissue, similar analyses were conducted on lymphocytes isolated from 16 FHP and 19 FHN subjects. There were no group differences in differential cell count or typing of isolated lymphocytes prepared by ficoll density gradient centrifugation. For each subject, there was a significant correlation between erythrocyte membrane Gs $\alpha$ and lymphocyte membrane Gs $\alpha$ (Fig. 4; $r=0.6, P$ $<0.0001$ ). Similar to the erythrocyte, enhanced expression of

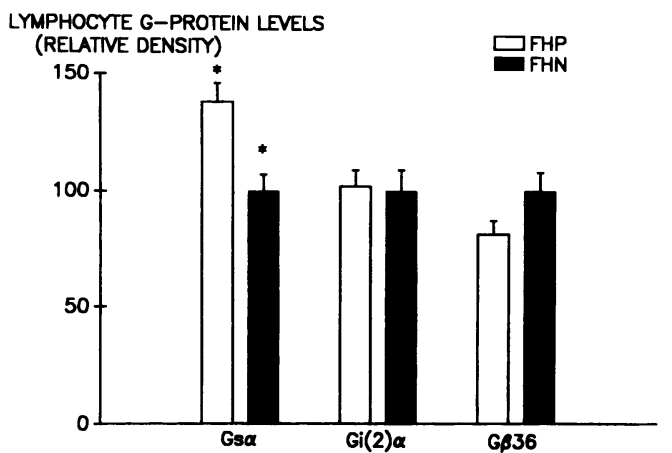

Figure 5. Comparison of lymphocyte membrane G-protein content by immunoblot analysis. ${ }^{*} P<0.02$.

Gs $\alpha$ was also documented in lymphocyte membranes from FHP subjects compared to FHN subjects (Fig. 5; FHP 138 \pm 9 ; FHN $100 \pm 9 ; P<0.02$ ).

Erythrocyte membrane Gsa content: matched sample analysis. The full-sample family history groups differed slightly (but not significantly) in current drinking practices (9 vs 8 drinks per week). For these reasons, FHP/FHN pairs were matched on age (within 4 yr), drinks per week (within 5 drinks), and gender. This yielded 21 matched pairs of subjects for analysis ( 20 male pairs and 1 female pair). These matched groups were very similar in age $(\mathrm{FHP}=23.3 \pm 0.6 \mathrm{yr} ; \mathrm{FHN}=23.1 \pm 0.6 ; t=0.29, P$ $>0.7$ ), and in drinks per week (FHP $=8.2 \pm 2.1$ drinks; FHN $=8.0 \pm 1.9$ drinks; $t=0.08, P>0.9)$. CT and immunoblot measures of Gs $\alpha$ correlated $r=0.69(P<0.001)$ in this sample of subjects. Neither measure was significantly correlated with age, or with drinks per week. Analyses of group differences in antisera measures of Gs $\alpha$ were conducted on the 21 matched pairs.

Using $t$ tests, FHP subjects had significantly higher Gs $\alpha$ expression than did FHN subjects, for Gs $\alpha$ antisera measures, ( $177 \pm 13$ vs. $102 \pm 8, t=5.0, P<0.001$ ), and for CT measures, $(214 \pm 32$ vs. $100 \pm 13, t=3.3, P<0.005)$. Because the antisera and CT distributions showed significant positive skew, group differences in the log-transformed scores were tested. FHP subjects had significantly higher scores than did FHN subjects for log-transformed antisera data $(t=5.71, P<0.001)$, and for $\log$-transformed CT data $(t=3.17, P<0.005)$. To verify the presence of robust group differences, we performed the nonparametric Wilcoxin two-sample rank sum test on the antisera and CT data. This nonparametric technique requires only the assumption of ordinal data. Once again, FHP subjects showed greater Gs $\alpha$ activity, as indicated by antisera data $(z=4.4, P$ $<0.001)$, and CT data $(z=2.2, P<0.05)$.

To estimate the proportion of variance in Gs $\alpha$ measures accounted for by family history, separate hierarchical multiple regression analyses were performed to predict antisera scores, and CT scores. Age and drinks per week were entered first, followed by family history, to estimate the effects of family history status after accounting for the effects of age drinks per week. For both antisera and CT data, neither age nor drinks per week were significant predictors in the regressions. Family history produced a large incremental R-squared value of 0.40 . The final beta of 0.63 for family history was highly significant $(P<0.001)$. For CT scores, family history produced an incremental gain of 0.23 in $r$-squared. The final beta of 0.48 for 


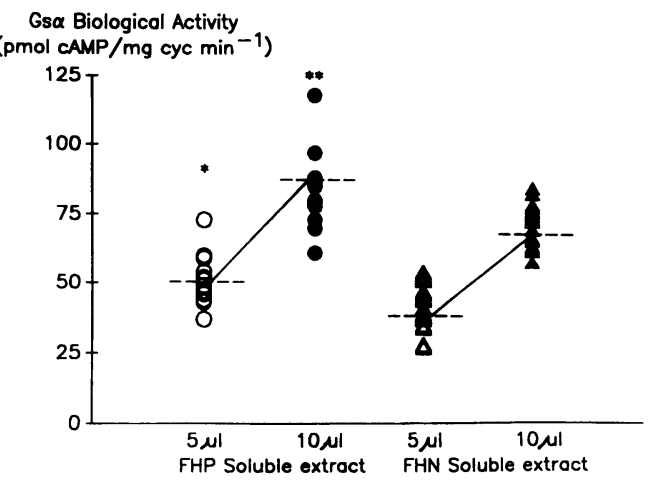

Figure 6. Activity of Gs $\alpha$ from erythrocyte membranes measured by reconstitution into Gs $\alpha$ deficient S49 lymphoma cyc membranes. Erythrocyte membranes from $\operatorname{FHP}(n=13)$ and FHN $(n=19)$ subjects were extracted in $0.2 \%$ Lubrol PX. Activity of Gs $\alpha$ in each extract was measured by correcting the Gs $\alpha$ deficiency of S49 lymphoma cyc membranes with the indicated amounts of erythrocyte extract in a complementation assay as described in Methods. Membranes were assayed in triplicate in the presence of $1 \mu \mathrm{M}$ isoproterenol and $10 \mu \mathrm{M} \mathrm{GTP} \gamma \mathrm{S} .{ }^{*} P$ $<0.01 ; * * P 0.025$

family history was significant $(P<0.005)$. (Results were very similar when log-transformed antisera and CT values were used in multiple regressions).

Gs $\alpha$ biological activity. To investigate whether increased levels of Gs $\alpha$ protein in erythrocyte membranes from FHP subjects was associated with increased Gs $\alpha$ bioactivity, a complimentation assay was performed in a subset of subjects. This assay is based on the ability of detergent extracts of erythrocyte membranes to reconstitute an active adenylyl cyclase in membranes from the $\mathrm{S} 49 \mathrm{cyc}^{-}$cell line, which genetically lacks Gs $\alpha$. Reconstitution assays demonstrated a dose-dependent biological activity of erythrocyte membrane Gs $\alpha$ with significantly greater Gs $\alpha$ biological activity from erythrocyte membranes of FHP ( $n$ =13) subjects than FHN $(n=19)$ subjects (Fig. 6).

Gis and $\beta$ subunit expression. Despite differences in levels of Gs $\alpha$, densitometric analysis of immunoblots did not demonstrate any statistical differences in the expression of either $\mathrm{Gi}(2) \alpha$ or $\mathrm{Gi}(3) \alpha$ in erythrocyte membranes of FHP subjects compared to membranes from FHN subjects (Fig. $1 C$ and Fig. 7). Pertussis toxin catalyzed [ $\left.{ }^{32} \mathrm{P}\right] \mathrm{ADP}$-ribosylation of a 42 - and $40-\mathrm{kD}$ protein corresponding to $\mathrm{Gi}(3) \alpha$ and $\mathrm{Gi}(2) \alpha$, respectively (Fig. $1 C$ ). The levels of erythrocyte Gi $\alpha$ forms determined

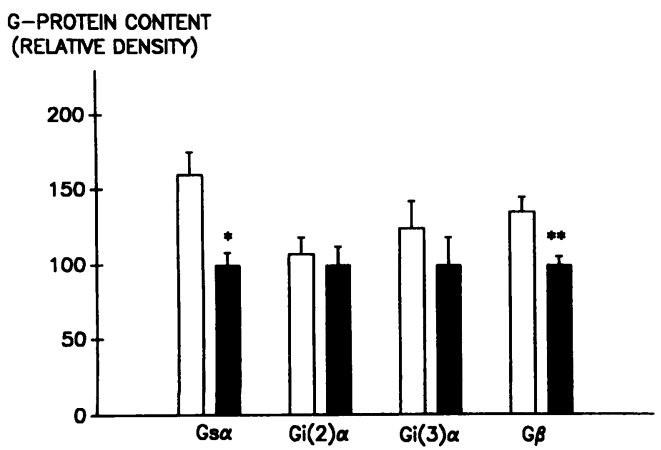

Figure 7. Comparison of erythrocyte membrane G-protein content by immunoblot analysis. $* P<0.001 ; * * P<0.05$.

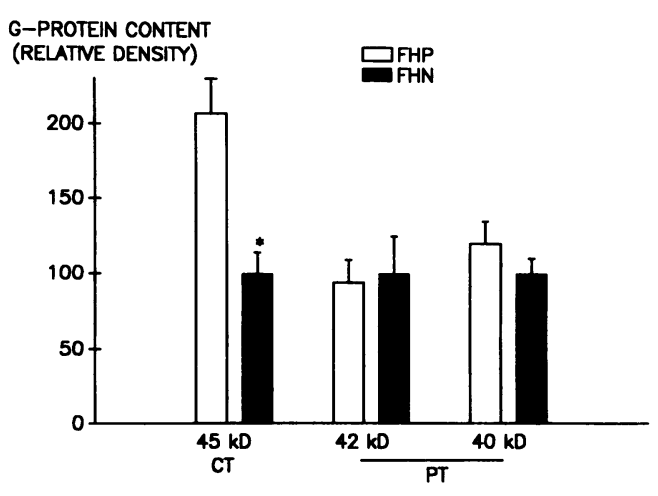

Figure 8. Comparison of erythrocyte membrane G-protein levels following bacterial toxin-dependent $\left[{ }^{32} \mathrm{P}\right] \mathrm{ADP}$-ribosylation. $\mathrm{CT}$, cholera toxin; PT, pertussis toxin; ${ }^{*} P<0.001$

by pertussis toxin-dependent $\left[{ }^{32} \mathrm{P}\right] \mathrm{ADP}$-ribosylation correlated significantly with levels of immunoactive Gi $\alpha$; no influence of family history was detected (Fig. 8). The $\mathrm{G} \beta$ antisera recognized a single $36-\mathrm{kD}$ band in erythrocyte membranes (Fig. $1 \mathrm{C}$ ). As opposed to $\mathrm{Gi}$ analysis, the groups did differ in measures of erythrocyte membrane $\beta_{36}$ subunit (Fig. 7; FHP $=135 \pm 11$ vs. FHN $=100 \pm 5.5, t=2.12, P<0.05)$. Immunoblot analysis did not show group differences in the expression of $\operatorname{Gi}(2) \alpha$, or $\mathrm{G} \beta_{36}$ in lymphocyte membranes (Fig. 5).

\section{Discussion}

Research over the past two decades has demonstrated a strong genetic predisposition to alcoholism (1-10). Adoption studies indicate increased frequency of alcoholism and drug abuse among children of alcoholics and drug abusers $(2,3)$. Concordance rates for alcoholism and drug abuse in monozygotic twins, who have identical genes, are higher than in dizygotic twins who share only half of their genes on average (2). It has been estimated from male twin studies that $38 \%$ of vulnerability to alcohol abuse, $60 \%$ of all vulnerability to alcohol abuse, $60 \%$ of all vulnerability to alcohol dependence, and $31 \%$ of vulnerability to drug abuse, can be attributed to genetic influences (2). Overall, sons of alcoholic fathers have a fourfold increased risk of developing alcoholism in their lifetime compared to the sons of nonalcoholic fathers (4).

Although as a group, sons of alcoholic fathers have an increased risk of developing alcoholism, not all sons inevitably develop this disorder. These findings have stimulated a search for biochemical, hormonal, neurophysiological, and genetic markers to identify nonalcoholic individuals at increased risk of developing alcoholism $(6-8,23)$. Several markers, such as altered peripheral opiate levels, P300 evoked potentials, adenylyl cyclase signal transduction, the monoamine oxidase system, alterations in phospholipase $\mathrm{D}$ metabolism, and a $\mathrm{D}_{2}$-dopamine receptor gene polymorphism have been proposed as predictors of increased risk for the development of alcoholism (68, 23). Alterations in other biochemical activities may be protective, such as inheritance of certain isoforms of aldehyde dehydrogenase that are associated with ethanol-induced flush (6).

This study shows that the levels of the stimulatory G-protein, $\mathrm{Gs} \alpha$, and the $\mathrm{G} \beta_{36}$ subunit are increased in erythrocytes 
membranes derived from a group of high risk nonalcoholics compared to a group of low risk nonalcoholics (group differences in lymphocyte membrane $\mathrm{G} \beta$ were not observed). The FHN and FHP groups were similar in age, race, years of school, and alcohol use patterns. Moreover, group differences remained robust when groups carefully matched on gender, age, and drinking were contrasted. Levels of Gs $\alpha$ were greater in both FHP and FHN subjects than in patients with AHO, an inherited syndrome in which decreased expression or function of Gs $\alpha$ results from heterozygous mutations in the GNAS (guanine nucleotide $\alpha$-subunit) gene (24-26). Levels of Gs $\alpha$ were increased in FHP subjects using two independent techniques, immunoblot analysis and cholera toxin-induced ADP-ribosylation. Moreover, addition of detergent-extracted G-proteins to S49 cyc-membranes, which genetically lack Gs $\alpha$, showed that increased Gs $\alpha$ protein from FHP subjects was fully bioactive. Overall, the similarity of results for the antisera and the CT data, and the consistent results obtained using four approaches to testing group differences $(t$ tests, $t$ tests for log-transformed data, nonparametric two-sample rank sum tests, and hierarchical multiple regression), provide converging evidence that a positive family history of alcoholism is associated with Gs $\alpha$ expression.

As only a subset of FHP subjects will develop problems with alcohol over their lifetime, it is not surprising that some FHP subjects had Gs $\alpha$ levels that were similar to those present in the low risk men. In a similar vein, a small percent of FHN subjects will go on to develop problems with alcohol, possibly explaining enhanced expression is some FHN subjects.

Can Gs $\alpha$ expression be a primary marker for alcoholism (i.e., one causal determinant of phenotype)? If this were true, we speculate that differential expression of Gs $\alpha$ among individuals may account for some of the individual differences in tissue sensitivity to ethanol. It is also possible that Gs $\alpha$ expression is a secondary marker, bearing no causal relationship to the alcoholism phenotype but genetically linked to some other causal factors. Regardless of whether Gs $\alpha$ could be a primary or secondary marker, it is important to determine if enhanced expression of Gs $\alpha$ is a useful predictor of individuals who will develop alcoholism. Markers for a genetic vulnerability to alcoholism could be used to select high-risk individuals for primary prevention and would allow investigations of environmental factors or pharmacological agents that may prevent expression of alcoholism in these high-risk individuals.

Alcohol can perturb the AC system both in vitro and in vivo $(11,27-35)$. Although freshly isolated lymphocytes from alcoholic subjects have reduced cAMP levels, after several generations in alcohol-free cultures, lymphocytes from alcoholics appear more sensitive to factors that stimulate cAMP production than lymphocytes from nonalcoholic controls (13). It is likely that the reduced cAMP levels found in freshly isolated lymphocytes (13) and platelets (36) from alcoholics are the result of prior alcohol exposure and it is possible that the alcohol-free environment allows the return of Gs $\alpha$ expression to higher steady state levels, as seen in our nonalcoholic FHP men. Because the mature erythrocyte does not contain an adenylyl cyclase, it is unclear whether the increase in Gs $\alpha$ expression we observe has a physiological effect on a cell's ability to generate cAMP. This is an important question for future research.

If, in fact, alcoholics and their family members have low AC activity, enhanced expression of Gs $\alpha$ may be compensatory for, and balancing the effects of an adenylyl cyclase with re- duced ability to generate cAMP $(36,37)$. In this scenario, membrane AC activity would be low or unchanged depending on the degree of Gs $\alpha$ compensation. However, if alcoholics and their family members do not have an AC with reduced activity, it is also plausible that enhanced expression of Gs $\alpha$ results in a cell more capable of generating cAMP following stimulation with ligand and ethanol. Regardless of whether a certain AC is dyfunctional in alcoholics, we speculate that genetic differences in G-protein expression allow for differential amplification of receptor-stimulated cAMP accumulation following ethanol exposure, and that resulting differences in cAMP levels allow for differences in the magnitude of certain forms of ethanol-induced activation (e.g., magnitude of reward) and tolerance. This may in part explain the observation of differential tissue sensitivity to ethanol among individuals.

Human studies have examined reactions to a single dose of ethanol in FHP and FHN nonalcoholics (7). Some investigators have found decreased responses to alcohol in FHP compared to FHN subjects using a variety of measures $(9,38,39)$. Many of these findings have not been replicated, and opposite results have also been reported $(7,40,41)$. The contradictory findings may be due in part to whether data were collected on the ascending or descending limb of the blood ethanol curve. In a review of the literature, Newlin and Thompson put forth a cogent model which proposes that sons of alcoholics exhibit greater effects of ethanol as blood ethanol levels rise and lesser effects of ethanol as blood ethanol levels fall, compared to the sons of nonalcoholics (7). The authors suggest that the prototypical FHP subject described by Schukit as being less sensitive to ethanol is an observation that applies mainly to the descending limb of the blood ethanol curve. This relative insensitivity of FHP compared to FHN men during the descending limb of the blood ethanol curve may be a function of the differences in their development of acute tolerance.

How do nonalcoholic individuals starting with enhanced expression of Gs $\alpha$ end up with reduced ability to make cAMP following the onset of alcoholism? Similar to the hypothesis proposed by Nagy et al. (13), we speculate that enhanced expression of Gs $\alpha$ sets the stage for the cell to initially undergo more pronounced activation of its AC system in the presence of alcohol, but that is then followed by more rapid and profound desensitization (e.g., tolerance). The enhanced expression of Gs $\alpha$ may explain the apparent phenomena of greater initial sensitivity to ethanol but more rapid development of tolerance to ethanol that develops in the offspring of alcoholics compared to nonalcoholics $(6,7)$. For example, following an ethanol challenge, FHP men have greater sensitivity during the ascending limb of the blood ethanol curve as determined by certain autonomic measures, EMG and EEG tracings, ataxic measures, and subjective sense of intoxication (7). During the falling limb of the blood ethanol curve FHP men develop greater acute tolerance to many of these same measures. By acute sensitivity, we refer to a more robust onset of a particular biologic affect initially induced by alcohol; by acute tolerance, we refer to a more rapid return to baseline of the particular biological effect over time as the blood ethanol level falls. It has been demonstrated that PKA (protein kinase A) is obligatory for the development of tolerance to ethanol (42-44). Enhanced expression of Gs $\alpha$ in FHP subjects may lead to a more robust accumulation of cAMP and activation of protein kinase $A$ resulting in a more profound desensitization. The more rapid onset of desensitiza- 
tion may explain the observations that lymphocytes and platelets from alcoholic subjects have reduced cAMP levels $(13,36)$.

Although the mechanism underlying increased Gs $\alpha$ and $\beta 36$ content is unclear, we speculate that differences in cortisol production between FHP and FHN subjects may account for some of the group differences in G-protein expression. For example, glucocorticoid exposure enhances Gs $\alpha$ and $\beta$ subunit expression in cultured cells (45-48). In addition, stress increases expression of Gs $\alpha$ as well as $\beta$ subunits and this effect can be blocked by adrenalectomy (48). There is increasing evidence that FHP subjects have altered dynamics of the hypothalmic-pituitaryadrenal axis compared to FHN $(38,40,49)$. This is not surprising when one considers that the $\mathrm{CRH}$ (corticotropin-releasing hormone) neuron, which is responsible for initiating the HPA axis stress response, is under inhibitory control by opiate producing neurons (e.g., arcuate nucleus). Animal and human studies are showing that endogenous opiates play an important role in ethanol-seeking behavior (50-52). It is plausible that if opiate activity differs in the FHP versus the FHN subjects, then a neuroendocrine system regulated by opiate activity (e.g., CRH neurons) will also differ in the two groups. It is possible that differences in cortisol production accounts for the group differences in G-protein expression.

In summary, compared to FHN nonalcoholic men, FHP nonalcoholic men had greater levels of the stimulatory G-protein, Gs $\alpha$ in erythrocyte and lymphocyte membranes. Enhanced expression of Gs $\alpha$ may be a marker for individuals at increased risk for the future development of alcohol abuse or alcoholism.

\section{Acknowledgments}

This work was supported by National Institutes of Health grants RO1AA09000 (G. S. Wand) and DK-34281 (M. A. Levine) as well as a gift from Alexander and Norma Lattman.

\section{References}

1. Cotton, N. S. 1979. The familial incidence of alcoholism: A review. $J$. Stud. Alcohol. 40:89-116.

2. Pickens, R. W., D. S. Svikis, M. McGue, D. T. Lykken, L. L. Heston, and P. J. Clayton. 1991. Heterogeneity in the inheritance of alcoholism. Arch. Gen. Psychiatry. 48:19-28.

3. Kendler, K. S., A. C. Health, M. C. Neale, R. C. Kessler, and L. J. Eaves. 1992. A population-based twin study of alcoholism in women. JAMA (J. Am. Med. Assoc.) 14:1877-1882.

4. Goodwin, D. W., F. Schulsinger, L. Hermansen, S. B. Guze, and G. Winokur. 1973. Alcohol problems in adoptees raised apart from alcoholic biological parents. Arch. Gen. Psychiatry. 28:238-243.

5. Cloninger, C. R., M. Bohman, and S. Sigvardsson. 1981. Inheritance of alcohol abuse: Cross-fostering analysis of adopted men. Arch. Gen. Psychiatry. 38:861-868.

6. Crabb, D. W. 1990. Biological markers for increased risk of alcoholism and for quantitation of alcohol consumption. J. Clin. Invest. 85:311-315.

7. Newlin, D. B., and J. B. Thomson. 1990. Alcohol challenge with sons of alcoholics: A critical review and analysis. Psychol. Bull. 108:383-402.

8. Devor, E. J., and C. R. Cloninger. 1989. Genetics of alcoholism. Annu. Rev. Genet. 23:19-36.

9. Schukit, M. S., S. C. Risch, and E. O. Gold. 1988. Alcohol consumption, ACTH level, and family history of alcoholism. Am. J. Psychiatry. 145:13911395.

10. Gianoulakis, C., D. Beliveau, P. Angelogiamni, M. Meaney, J. Thavundayil, V. Tawar, and M. Dumas. 1989. Different pituitary $\beta$-endorphin and adrenal cortisol response to ethanol in individuals with high and low risk for future development of alcoholism. Life Sci. 45:1097-1109.

11. Hoffman, P. L., and B. Tabakoff. 1990. Ethanol and guanine nucleotide binding proteins: a selective interaction. FASEB (Fed. Am. Soc. Exp. Biol.) J. 4:2612-2622.

12. Diamond, I., B. Wrubel, W. Estrin, and A. Gordon. 1987. Basal and adenosine receptor-stimulated levels of cAMP and reduced in lymphocytes from alcoholic patients. Proc. Natl. Acad. Sci. USA. 84:1413-1416.

13. Nagy, L. E., I. Diamond, and A. Gordon. 1988. Cultured lymphocytes from alcoholics have altered cAMP signal transduction. Proc. Natl. Acad. Sci. USA. 85:6973-6926.

14. Palmour, R., A. Smith, S. Parboosingh, S. Merani, M. Gupta, and F. Ervin. 1992. Phenotypic markers of susceptibility to familial alcoholism. Proceedings of the 21st International Medical Advisory Conference. The Alcoholic Beverage Medical Research Foundation. 122-127.

15. Palmour, R., D. Grbavic, F. Ervin, L. Staley, and D. Mash. 1993. Increased signal transduction in lymphocytes cultured from alcohol preferring vervet monkeys. Neuroscience. 210:610.

16. Andreasen, N. C., J. Endicott, R. L. Spitzer, and G. Winodur. 1977. The family history method using diagnostic criteria: Reliability and validity. Arch Gen. Psychiatry. 34:1229-1235.

17. Levine, M. A., R. W. Downs Jr., M. Singer, S. J. Marx, G. D. Aurbach, and A. M. Spiegel. Deficient activity of guanine nucleotide regulatory protein in erythrocytes from patients with pseudohypoparathyroidism. 1980. Biochem. Biophys. Res. Commun. 94:1319-24.

18. Waltman, C., M. A. Levine, E. McCaul, D. Svikis, and G. Wand. 1993 Enhanced expression of Gi $\alpha(2)$ decreases adenylyl cyclase activity in lymphocytes of abstinent alcoholics. Alcohol. Clin. Exp. Res. 17:315-320.

19. Patten, J., and M. A. Levine. 1990. Immunochemical analysis of the alpha subunit of the stimulatory G-protein of adenylyl cyclase in patients with Albright's Hereditary osteodystrophy. J. Clin. Endocrinol. Metab. 71:1208-1214.

20. Levine, M. A., A. M. Feldman, J. D. Robishaw, P. W. Ladenson, T. G. Ahn, J. F. Moroney, and P. M. Smallwood. Influence of thyroid hormone status on expression of genes encoding G protein subunits in the rat heart. J. Biol. Chem. 265:3553-3560.

21. Kuchler, K., H. G. Dohlman, and J. Thorner. 1993. The $\alpha$-factor transporter and cell polarity in the yeast Saccharomyces cerevisiae. J. Cell Biol. 120(5):12031215.

22. Levine, M. A., C., R. W. Downs Jr., and A. M. Spiegel. 1983. Deficient guanine nucleotide regulatory unit activity in cultured fibroblast membranes from patients with pseudohypoparathyroidism type I. J. Clin. Invest. 72:316-324.

23. Uhl, G. R., A. M. Persico, and S. S. Smith. 1992. Current excitement with $\mathrm{D}_{2}$ dopamine receptor gene alleles in substance abuse. Arch. Gen. Psychiatry. 49:157-160.

24. Levine, M. A., T. G. Ahn, S. F. Klupt, K. D. Kaufman, P. M. Smallwood, H. R. Bourne, K. A. Sullivan, and C. Van Dop. 1988. Genetic deficiency of the alpha subunit of the guanine nucleotide-binding protein, $G_{s} \alpha$ as the molecular basis for Albright's hereditary osteodystrophy. Proc. Natl. Acad. Sci. USA. 85:617-621.

25. Patten, J. L., D. R. Johns, M. D., D. Valle, M. D., C. Eil, M. D., Ph.D., P. A. Gruppuso, M. D., G. Steele, B. A., P. M. Smallwood, B. A., and M. A. Levine, M. D. 1990 . Mutation in the gene encoding the stimulatory $G$ protein of adenylyl cyclase in Albright's hereditary osteodystrophy. N. Engl. J. Med. 322:1412-1419.

26. Levine, M. A., T. S. Jap, and W. Hung. 1985. Infantile hypothyroidism in two sibs: an unusual presentation of pseudohypoparathyroidism type la. $J$. Pediatr. 107:912-923.

27. Mochly-Rosen, D., F. U. Chang, L. Cheever, M. Kim, I. Diamond, and A. S. Gordon. 1988. Chronic ethanol causes heterologous desensitization of receptors by reducing $\alpha_{\mathrm{s}}$ messenger RNA. Nature (Lond.). 333:848-850.

28. Wand, G., and M. A. Levine. 1991. Hormonal tolerance to ethanol is associated with decreased expression of the GTP-binding protein, Gs $\alpha$, and adenylyl cyclase activity in ethanol-treated LS mice. Alcohol Clin. Exp. Res. 15:705710 .

29. Wand, G., A. Diehl, M. A. Levine, D. Wolfgang, and S. Samy. 1993. Chronic Ethanol treatment increases expression of inhibitory G-proteins and reduces adenylyl cyclase activity in the central nervous system of two lines of ethanol-sensitive mice. J. Biol. Chem. 268:2595-2601.

30. Goldstein, D. B., and A. Goldstein. 1961. Possible role of enzyme inhibition and repression in drug tolerance and addiction. Biochem. Pharmacol. 8:48.

31. Rabin, R. A. 1990. Direct effects of chronic ethanol exposure on $\beta$ adrenergic and adenosine-sensitive adenylate cyclase activities and cyclic AMP content in primary cerebellar cultures. J. Neurochem. 55:122-128.

32. Rabin, R. A. 1990. Chronic ethanol exposure of PC12 cells alters adenylate cyclase activity and intracellular cyclic AMP content. J. Pharmacol. Exp. Ther. 252:1021-1027.

33. Richelson, E., S. Stenstrom, C. Forray, L. Enloe, and M. Pfenning. 1986 Effects of chronic exposure to ethanol on the prostaglandin E1 receptor-mediated response and binding in a murine neuroblastoma clone (N1E-115). J. Pharmacol. Exp. Ther. 239:687-692.

34. Gordon, A. S., K. Collier, and I. Diamond. 1986. Ethanol regulation of adenosine receptor-stimulated cAMP levels in a clonal neural cell line. 1986. An in vitro model of cellular tolerance to ethanol. Proc. Natl. Acad. Sci. USA. 83:2105-2108.

35. Gordon, A. S. D. Mochly-Rosen, and I. Diamond. 1992. Alcoholism and alcohol abuse: possible G protein disorders. Chapter 8 In Dysfunction of G- 
Protein Linked Cascades in Cellular Physiology. G. Milligan, and MJO Wakelam, editors. Academic Press LTD, London 191-216.

36. Tabakoff, B., P. L. Hoffman, J. M. Lee, T. Saito, B. Willard, and F. De Leon-Jones. 1988. Differences in platelet enzyme activity between alcoholics and nonalcoholics. N. Engl. J. Med. 318:134-139.

37. Hellevuo, K., M. Yoshimur, M. Kao, P. L. Hoffman, D. M. Cooper, and B. Tabokoff. 1993. A novel adenylyl cyclase sequence cloned from the human erythroleukemia cell line. Biochem. Biophys. Res. Commun. 192:311-318.

38. Schukit, M. A. 1984. Differences in plasma cortisol after ingestion of ethanol in relatives of alcoholics and controls: Preliminary results. J. Clin. Psychiatry 45:374-376.

39. Schukit, M. A., E. Gold, and C. Risch. 1987. Serum prolactin levels in sons of alcoholics and control subjects. Am. J. Psychiatry. 144:854-859.

40. Gianoulakis, C., D. Beliveau, and P. Angelogiamni. 1988. Different pituitary $\beta$-endorphin and adrenal cortisol response to ethanol in individuals with high and low risk for future alcoholism. Life Sci. 45:1097-1109.

41. Lex, B. W., J. E. Ellingboe, S. K. Teoh, J. H. Mendelson, E. Rhoades. 1991. Prolactin AND cortisol levels following acute ethanol challenges in women with and without a family history of alcoholism. Alcohol. 8:383-387.

42. Rabin, R. A. 1993. Ethanol-induced desensitization of adenylate cyclase: role of the adenosine receptor and GTP-binding proteins. J. Pharmacol. Exp. Ther. 264:977-983.

43. Rabin, R. A., A. M. Edelman, and J. A. Wagner. 1992. Activation of protein kinase A is necessary but not sufficient for ethanol-induced desensitization of cyclic AMP production. J. Pharmacol. Exp. Ther. 262:257-262.
44. Rabin, R. A. 1991. Chronic ethanol exposure has a dual effect on adenylate cyclase activity and cyclic AMP content. Ann. N.Y. Acad. Sci. 625:441-443.

45. Chang, F. H., and H. R. Bourne. 1987. Dexamethasone increases adenylyl cyclase activity and expression of the $\alpha$-subunit of $\mathrm{G}_{\mathrm{s}}$ in $\mathrm{GH} 3$ cells. Endocrinology. 121:1711-1715.

46. Morrill, A. C., D. Wolfgang, M. A. Levine, and G. S. Wand. 1993. Stress Alters Adenylyl cyclase Activity in the Pituitary and Frontal Cortex of the Rat. Life Sci. 53:1719-1727.

47. Saito, N., X. Guitart, M. Hayward, J. Tallman, R. Dumon, and E. Nestler. 1989. Corticosterone differentially regulates the expression of $\mathrm{G}_{\mathrm{s}} \alpha$ and $\mathrm{G}_{\mathrm{i}} \alpha \mathrm{mRNA}$ and protein in rat cerebral cortex. Proc. Natl. Acad. Sci. USA. 86:3906-3910.

48. Wolfgang, D., I. Chen, and G. S. Wand. Effects of restraint stress on components of adenylyl cyclase signal transduction in the rat hippocampus. Neuropsychopharmacology. In Press.

49. Waltman, C., B. McCaul, and G. S. Wand. Differential plasma ACTH response to exogenous $\mathrm{CRH}$ in subjects at high and low risk for alcoholism. Alcohol. Clin. Exp. Res. In Press.

50. Froehlich, J. C., and T-K. Li. 1991. Animal models for the study of alcoholism: utility of selected lines. J. Addict. Dis. 10:61-71.

51. Froehlich, J. C., M. Zweifel, J. Harts, L. Lumeng, and T-K. Li. 1991. Importance of delta opioid receptors in maintaining high alcohol drinking. Psychopharmacology. 103:467-472.

52. Schuckit, M. A., T-K. Li, C. R. Cloninger, and R. A. Deitrich. 1985. Genetics of alcoholism (clinical conference). Alcohol. Clin. Exp. Res. 9:475-492. 